\title{
Soft-tissue matching methods for lung cancer radiotherapy - benefits, limitations and margin determination
}

Rahma, Fatma; Ottosson, Wiviann; Behrens, Claus F.; Sjöström, David; Sibolt, Patrik

\section{Published in:}

Physica Medica

Link to article, DOI:

10.1016/j.ejmp.2014.07.268

Publication date:

2014

Document Version

Publisher's PDF, also known as Version of record

Link back to DTU Orbit

Citation (APA):

Rahma, F., Ottosson, W., Behrens, C. F., Sjöström, D., \& Sibolt, P. (2014). Soft-tissue matching methods for lung cancer radiotherapy - benefits, limitations and margin determination. Physica Medica, 30, e93-e94. https://doi.org/10.1016/j.ejmp.2014.07.268

\section{General rights}

Copyright and moral rights for the publications made accessible in the public portal are retained by the authors and/or other copyright owners and it is a condition of accessing publications that users recognise and abide by the legal requirements associated with these rights.

- Users may download and print one copy of any publication from the public portal for the purpose of private study or research.

- You may not further distribute the material or use it for any profit-making activity or commercial gain

- You may freely distribute the URL identifying the publication in the public portal 


\section{IMAGING PERFORMANCE OF A GD ${ }_{2} \mathrm{O}_{2} \mathrm{~S}$ :PR,CE,F SCINTILLATOR COATED CMOS IMAGING SENSOR}

C. Michail a, I. Seferis ${ }^{\text {a,b }}$, I. Valais ${ }^{\text {a }}$, V. Koukou ${ }^{c}$, N. Kalyvas ${ }^{\text {a }}$, A. Bakas ${ }^{\mathrm{d}}$, G. Fountos ${ }^{\mathrm{a}}$, I. Kandarakis ${ }^{\mathrm{a}}$. ${ }^{\mathrm{a}}$ Department of Biomedical Engineering, Technological Educational Institute of Athens,122 10 Athens, Greece; ${ }^{\mathrm{b}}$ Faculty of Chemistry, Wroclaw University, $14 \mathrm{~F}$ Joliot-Curie Street, 50-383 Wroclaw, Poland; ' ${ }^{\mathrm{C}}$ Department of Medical Physics, School of Medicine, University of Patras, Rion GR 26504, Greece; ${ }^{\mathrm{d}}$ Medical Radiological Technology, Faculty of Health and Caring Professions / Technological Educational Institution of Athens, Athens, Greece

Aim: The aim of the present study was to investigate the imaging performance of gadolinium oxysulfide powder scintillators, doped with praseodymium, cerium and fluorine $\left(\mathrm{Gd}_{2} \mathrm{O}_{2} \mathrm{~S}: \mathrm{Pr}, \mathrm{Ce}, \mathrm{F}\right)$ coupled to a high resolution active pixel CMOS imaging sensor.

Methods: Gd2O2S:Pr,Ce,F is a non-hygroscopic material, emitting green light with short decay time. For the purposes of this study, a scintillating screen with coating thickness of $35.7 \mathrm{mg} / \mathrm{cm}^{2}$, was prepared in our laboratory from powder (Phosphor Technology, Ltd) by sedimentation on silica substrates. The CMOS sensor was coupled to the $\mathrm{Gd}_{2} \mathrm{O}_{2} \mathrm{~S}$ :Pr,Ce, $\mathrm{F}$ scintillator screen. Imaging performance was obtained by means of experimentally determined parameters such as the signal transfer properties (STP), the modulation transfer function (MTF) and the normalized noise power spectrum (NNPS). Measurements were performed using the standard IEC-RQA5 radiation beam quality (70 kVp).

Results: It was found that the detector response function was linear for the exposure range under investigation. At $70 \mathrm{kVp}$, under the RQA 5 conditions, the $\mathrm{Gd}_{2} \mathrm{O}_{2} \mathrm{~S}: \mathrm{Pr}, \mathrm{Ce}, \mathrm{F} / \mathrm{CMOS}$ combination can resolve $6.88 \mathrm{cy}-$ cles $/ \mathrm{mm}$, at MTF10\% and the noise levels were found to decrease from $6.42 \times 10^{-6} \mathrm{~mm}^{2}$, at 1.38 cycles $/ \mathrm{mm}$ to less than $2.23 \times 10^{-6} \mathrm{~mm}^{2}$ at $5.2 \mathrm{cy}-$ cles $/ \mathrm{mm}$.

Conclusion: MTF and NNPS values of the $\mathrm{Gd}_{2} \mathrm{O}_{2} \mathrm{~S}$ : $\mathrm{Pr}, \mathrm{Ce}, \mathrm{F} / \mathrm{CMOS}$ combination were found with high values suggesting an acceptable imaging performance showing potential interest for non-CT medical imaging (i.e. dental radiology) or industrial digital radiography.

Acknowledgement: This research has been co-funded by the European Union (European Social Fund) and Greek national resources under the framework of the "ARISTEIA" project MISCIRLU code 1476 of the "Education \& Lifelong Learning" Operational Programme.

\section{APPLICATION OF TUMOR BED BOOST BY TWO DIFFERENT METHODS}

Zygogianni Anna M.D,Ph.Da, Kouloulias Vassilios M.Sc., M.D, Ph.D ${ }^{b}$, Kyrgias George M.D,Ph.D ${ }^{c}$, Armpilia Christina M.Sc ${ }^{\mathrm{a}}$, Antypas Christos M.Sc., Ph.D ${ }^{a}$, Theodorou Kiki M.Sc., Ph.D ${ }^{c}$, Kouvaris John M.D,Ph.D ${ }^{\mathrm{a}}$. ${ }^{\mathrm{a}}$ Kapodistrian University of Athens, Medical School, 1st Radiology Department, Aretaieion Hospital, Greece; ${ }^{\mathrm{b}}$ Kapodistrian University of Athens, Medical School, 2st Radiology Department, Attikon Hospital, Greece; ${ }^{\mathrm{C}}$ University of Thessalia, Medical School, Radiotherapy Department of Larissa, Greece

Aim: We evaluate acute and late radiation toxicity, and the effectiveness of the radiation therapy of the two radiotherapeutic hypofractionated schedules using two different planning techniques of delivering radiation boost using 3D conformal radiation therapy (3DCRT).

Method: Eight one patients were studied, between May 2004 and December 2010. The patients were retrospectively selected regarding with either concomitant (group A) or sequential (group B) boost for tumor bed in two groups. In the first group, 27 patients received $2.3 \mathrm{~Gy}$ up to $46 \mathrm{~Gy}$ in the whole breast tissue and it was added a concomitant boost covering tumor bed as a second daily fraction of $0.4 \mathrm{~Gy}$, so that the total tumor bed boost was $54 \mathrm{~Gy}$. In the second group, 54 patients received radiotherapy with a total prescription dose of $53 \mathrm{~Gy}$ by $2.65 \mathrm{~Gy}$ per fraction, in 20 fractions, over 25 days. The last four fractions were delivered as a sequential tumor boost. Using the linear quadratic model, BED has been calculated for the whole breast dose and total boost dose volumes. These values in the first radiotherapy regimen used were $72.5 \mathrm{~Gy}_{4}$ and $90.5 \mathrm{~Gy}_{4}$, respectively. In the second one they were $70.5 \mathrm{~Gy}_{4}$ and $88.1 \mathrm{~Gy}_{4}$, respectively.

Results: The statistical analysis of the comparison between the two methods, showed that cosmetic results, in terms of skin toxicity score, was significantly worse in integrated boost group, for time ranging from the completion of radiotherapy until 12th months thereafter. After the first year post irradiation the toxicity was reduced to minimum in both groups, while the Kruskal-Wallis $\mathrm{H}$ Test showed a significant $(\mathrm{P}<0.05)$ superiority of group B in skin toxicity in terms of overall follow-up. With a median follow up of 24 months, no patient showed local or regional disease recurrence.

Conclusions: There were significant differences in the scoring of erythema, in patients receiving an incorporated boost compared with patients treated by sequential boost. The higher skin reactions were observed in the group with the concomitant boost and especially identified in the application area of the intergraded boost. This can be avoided by the application of IMRT technique whereas the dose distribution is more smooth and homogeneous

\section{SOFT-TISSUE MATCHING METHODS FOR LUNG CANCER RADIOTHERAPY - BENEFITS, LIMITATIONS AND MARGIN DETERMINATION}

Fatma Rahma ${ }^{\mathrm{a}, \mathrm{b}}$, Wiviann Ottosson ${ }^{\mathrm{a}, \mathrm{c}}$, Claus F. Behrens ${ }^{\mathrm{a}}$, David Sjöström ${ }^{\text {a }}$, Patrik Sibolt ${ }^{\mathrm{a}}$. ${ }^{\mathrm{a}}$ Department of Oncology, Radiotherapy Research Unit, HerlevHospital, University of Copenhagen, DK-2730 Herlev, Denmark; ${ }^{\mathrm{b}}$ Department of Medical Radiation Physics, Clinical Sciences, Lund University, Sweden; ${ }^{\mathrm{C}}$ Center for Nuclear Technologies, TechnicalUniversity of Denmark, DTU Risø Campus, DK-4000 Roskilde, Denmark

Background: The purpose of this study was to evaluate five different CBCT semi-automatic soft-tissue match methods for lung cancer patients and to calculate the corresponding CTV to PTV margins, both for primary tumor and lymphnodes.

Material and methods: For 23 lung cancer patients (16 NSCLC, 7 SCLC) treated with radiotherapy, 135 weekly CBCT set-up images were retrospectively matched to the planning CTs byfive different match methods using the registration software Offline Review, version 10.0 (Varian Medical Systems). Four match methods utilized the volume of interest (VOI) of the 4DCT defined GTV, including the internal motion (GTV-T/ IM), plus a 2, 5, 10 or 20 mmsymmetrical margin, respectively. The fifth match method used a square VOI enclosing the GTV-T with a $10 \mathrm{~mm}$ symmetrical margin. An intensity range of $[-150 ; 150]$ HU was used for automatic soft-tissue matches. Residual GTV-T/IM set-up deviations in all directions were studied for each match and PTV-T margins were calculated. Additionally, stable surrogates close to GTV-N was used for the residual GTV-N set-up deviation measurements and PTV-N margin calculations.

Results: All match methods gave similarresidual GTV-T/IM set-up deviations, ranging between $[0 ; 3] \mathrm{mm}$ ( $62 \%$ within $0-1 \mathrm{~mm}, 34 \%$ within $1-2$ $\mathrm{mm}$, and $4 \%$ within $2-3 \mathrm{~mm}$ ), resulting in $[5.2 ; 5.8] \mathrm{mm}$ PTV-T margins. Match methods utilizing larger VOIs were more stable compared to match methods using smaller VOIs. Auto match on small targets $\left(<3 \mathrm{~cm}^{3}\right)$ was problematic, and not possible for match method 5 . For $77 \%$ of the patients with lymph nodes, the main bronchi area was a suitable stable surrogate. For the remaining lateral GVT-Ns the aortic arch and the main pulmonary artery were suitable as surrogates. Residual GTV-N set-up deviations ranged between $[-8 ; 10] \mathrm{mm}$ resulting in PTV-N margins between $[6 ; 9.8]$ $\mathrm{mm}$.

Discussion: Forsemi-automatic soft-tissuematch on the primary tumor,match within GTV-T/IM witha 10 or 20 mmmargin extensionused as matching VOIs were most appropriate. For small tumors $\left(<3 \mathrm{~cm}^{3}\right)$, matching manually on GTV-T/IM itself is advisable. The main bronchi area is a suitable surrogate primarily for centrally positionedmediastinal GTV-N. 


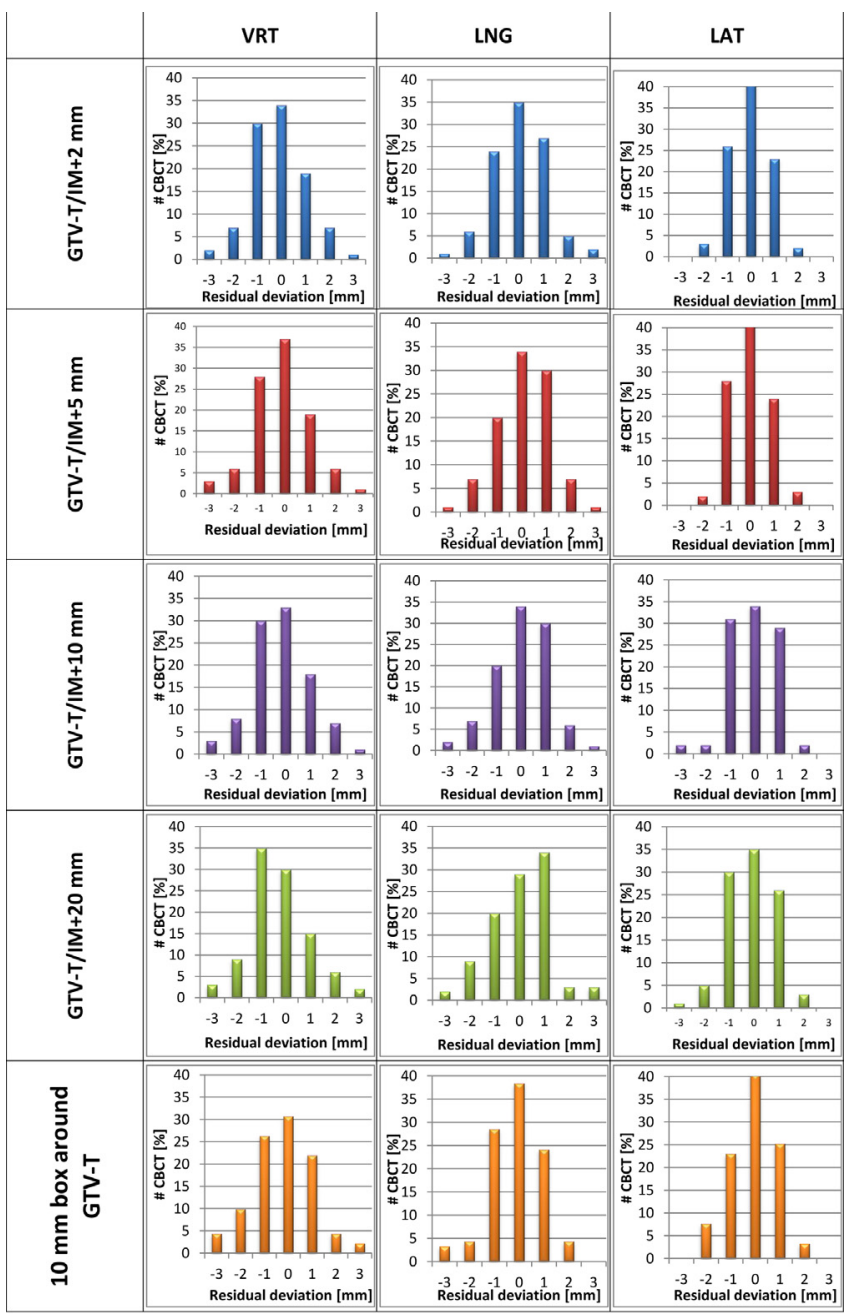

Figure 1. GTV-T/IM residual deviation after 3DOF soft-tissue match (utilizing GTV-T/ IM plus a 2, 5, 10 and $20 \mathrm{~mm}$ symmetrical margin, and square VOI enclosing the GTV-T with a $10 \mathrm{~mm}$ symmetrical margin).

\section{MODELLING BIOGRAPH 2 PET/CT SCANNER WITH GATE}

D. Nikolopoulos ${ }^{\text {a }}$, I. Valais ${ }^{\text {b }}$, C. Michail ${ }^{\mathrm{b}}$, S. Kottou ${ }^{\mathrm{c}}$, N. Chatzisavvas ${ }^{\mathrm{a}}$, P. Yannakopoulos ${ }^{\mathrm{a}}$, V. Malaxianakis ${ }^{\mathrm{b}} \cdot{ }^{\mathrm{a}}$ Department of Computer Electronic Engineering, Technological Education Institute of Piraeus, Greece, Petrou Ralli \& Thivon 250, 122 44, Aigaleo, Athens, Greece; ${ }^{\mathrm{b}}$ Department of Biomedical Engineering, Technological Educational Institute of of Athens, Agiou Spiridonos, 12210, Aigaleo, Greece; ${ }^{\mathrm{C}}$ Medical Physics Department, Medical School, University of Athens, Greece

Background: A commercial PET scanner (Siemens, Biograph 2) previously tested through experiments according to the NEMA NU-2-2001 protocol, was simulated, using the GATE v.6.1 open source software.

Materials and methods: The study aimed: (a) to port previously developed and validated GATE codes to the more stable version of GATE v.6.1; (b) to evaluate the overall applicability and validity of the model and to investigate potential sources of bias (c) to examine possible alterations in the results caused by different employed sources, i.e. F-18 (Fluorine-18), O-15 (Oxygen-15) and C-11 (Carbon-11). All modules of the Biograph 2 scanner were described in GATE, namely the detector ring, crystal blocks, PMTs, shielding, electronics etc. In addition, the energy and spatial resolution of the employed detectors and their contribution to the overall system's efficiency were taken into account.
Results: The results derived by the simulations with GATE, were then compared to the experimental data obtained by the NEMA NU-2-2001 protocol. Scatter fraction, count loses and randoms were the main points of interest.

Discussion: Good agreement was observed between the results of the experimental data and GATE simulated results.

\section{ASSESSMENT OF DOSE ADMINISTRATION CONSISTENCY IN PET/CT}

N. Sgouros ${ }^{a}$, T. Stroubinis ${ }^{a}$, A. Samartzis ${ }^{a}$, P. Rondogianni ${ }^{a}$, I. Datseris ${ }^{a}$. ${ }^{a}$ Department of Nuclear Medicine, Evangelismos General Hospital, Athens, Greece

Background: In this work we assess the consistency of the dose administration process of ${ }^{18} \mathrm{~F}$-FDG in the PET/CT establishment of Evangelismos General Hospital. In detail, we retrospectively assess the dose administration accuracy for a three year period and evaluate the dose consistency over two shifts. Both shifts utilized an ANZAI medical semi-automated dispenser. In the first shift trainees are supervised by experienced medical physicists while in the second shift dose administration was performed by experienced professionals.

Materials and methods: The data utilized in this study were collected from 2011 through the end of 2013 and were properly anonymized by removing patients' demographic details. The resulting sample after removing invalid entries contains 4038 records.

In order to robustly assess the administration accuracy the initially prepared $(P D)$ and syringe residual doses $(R D)$ were measured and the nominal dose $(N D)$ for each patient was calculated. In order to provide a robust and simple measure we utilized ratio $r$ calculated by Eq. 1 and already proposed by the authors.

$r=\frac{P D-R D}{N D}$

Results: In order to examine the accuracy of dose administration the Shapiro - Wilk test is us ed for testing normality of the $r$ values distributions prior to using the $\mathrm{t}$-test. The mean values, standard deviations and the p-values for the Shapiro - Wilk test and the t-test are summarized in Table 1.

Table 1. Calculated Statistics

\begin{tabular}{|c|c|c|c|c|}
\hline \multirow[t]{2}{*}{ Groups } & \multirow[t]{2}{*}{ Mean value } & \multirow{2}{*}{$\begin{array}{l}\text { Standard } \\
\text { Deviation }\end{array}$} & \multicolumn{2}{|l|}{ p-values } \\
\hline & & & Shapiro - Wilk & t-test \\
\hline Trainees & 0.9849 & 0.054 & 0.2538 & 0.8539 \\
\hline Professionals & 0.9882 & 0.043 & 0.3102 & \\
\hline
\end{tabular}

As shown in Table 1 both group samples follow the normal distribution ( $p>0.05$ ) and have mean values very close to unity which is in line with the design of quantity $r$. Furthermore, comparison of the standard deviations qualifies both samples for the t-test. The t-test shows ( $p>0.05)$ that the two populations have normal distributions with equal mean values.

Discussion: The results show that there is no significant difference in dose administration distributions between trainees and professionals. This fact is attributed in part to the semi-automated dispenser used in the process and in part to the standardization of the process and supervision of the medical physicists during the shift where trainees administer the doses. Hence consistent and homogeneous dose administration is achieved throughout both shifts assuring proper dose delivery to the patients of the PET/CT setup. 